\title{
Mind the evaluation gap: reviewing the assessment of architectural research in the Netherlands
}

Frank van der Hoeven

The definition of research quality is directly linked to public funding access in countries like the United Kingdom, Australia and the Netherlands. Architecture, as a design discipline, faces the problem that it has limited access to these resources. It experiences a so-called evaluation gap. Its research performance does not easily fit the conventional moulds commonly used to assess quality. Assessments are increasingly based on the analysis of indexed journals, while indexes (such as the ISI) have, so far, mostly neglected the arts and humanities to which architecture may be assumed to belong. Schools of architecture have to face this matter head-on if they want to survive in times of austerity, and they need to do so sooner rather than later. They have to decide whether they want to continue to push for the acceptance of disciplinespecific performance indicators or whether they would rather adapt to the standards and dissemination practices that characterise more established fields of scientific research. The direction they choose will inevitably shape future research in architecture.

The Dutch academic debate on the evaluation of research in design and engineering disciplines has recently evolved to a point at which it is now possible to make such a choice. Two key investigations, completed in 2010, shed light on this matter: the report on 'Evaluating Research in Context' by the Rathenau Institute, and the framework for 'Quality Assessment in the Design and Engineering Disciplines' by the Royal Netherlands Academy of Arts and Sciences (KNAW). This article provides a framework for understanding these reports by placing them in the context of the 2010 Netherlands research assessment exercise in Architecture and the Built Environment, with specific reference to the case of the Faculty of Architecture at TU Delft. By doing so, this paper aims to offer insight into the recent debate on the scientific quality and societal relevance of architecture research in the Netherlands, one of Europe's leading architectural cultures. The debate has clear implications for the broader disciplines of design, engineering, and creative arts, all of which seem to struggle with securing research funding, and with the corresponding shape of their research. The final goal of the article is to formulate a pragmatic approach that will allow schools of architecture to advance their research while staying true to the specifics of their field.

\section{A victim of assessment}

Since 1993, publicly funded research in the Netherlands has been subject to a national evaluation system. Similar systems are in place in countries such as the United Kingdom and Australia. This system is supervised by the Royal Netherlands Academy of Arts and Sciences (KNAW), the Netherlands Organisation for Scientific Research (NWO) and the Association of Universities in the Netherlands (VSNU). ${ }^{1}$ Together, these organisations ensure that publicly funded research is evaluated once every six years via a peer review assessment according to a periodically updated standard evaluation protocol (SEP). The institute awaiting assessment performs a selfevaluation to be used by the review committee in preparation for the site visit. Based on both the selfevaluation and the site visit, the review committee writes an assessment report. This assessment report is intended to help the research organisation to make better decisions about future research, research management and research policy.

The first such assessment of Dutch architecture research took place in 1997 and included research conducted by the Faculty of Architecture at the Delft University of Technology (TU Delft). The review committee was chaired by Prof. Hans-Wolf Reinhardt (University of Stuttgart), and among its members was Peter Nijkamp, who went on to serve as chair of the NWO from 2002-08. The review committee came to the following conclusion:

A fundamental problem in reviewing the research performance of architecture is that there are no clear-cut criteria for research in architecture. Architecture is neither science nor technology. It contains aspects of technology and aspects of science. It contains aspects of social sciences but it is less empirical. Architecture depends on intuition, ideas, sometimes also on ideology. Some facets of art are present. Architecture depends a great deal on persons, on 
individual personalities who create new things, which imprint the landscape, the town, neighbourhoods etc. The central product (one might say 'experiment') of architecture is design, but design is simply not recognized as research. This suggests that a core activity of a faculty of architecture does not contribute to scientific quality, productivity, and relevance. There is a systemic error in assessing the performance of a faculty of architecture since a large part and a most important part cannot be assessed by the rules (which apply to scientific research).

[...] The Review Committee has felt that architecture is not adequately represented in NWO and that this situation should be improved. ${ }^{2}$

It is difficult to determine whether the review committee's observation is a case of 'special pleading, ${ }^{3}$ (arq 14.1, pp. 11-16) (architectural research is fine; the assessment system is inadequate and incapable of measuring this), or whether, on the other hand, the observation stems from a bias that underestimates the value of design and engineering (architecture research is fundamentally flawed; there is nothing wrong with the assessment system). Regardless of the answer, the conclusions of the review committee are based on significant omissions and, retrospectively, have proven counterproductive.
The review committee refers to technology, art and social science in an attempt to determine the proper position of architecture research. In doing so, the review committee seems unaware of the general consensus that the core of the faculty's research (architecture) is a humanities discipline.

The review committee seemed unfamiliar with the realities inherent to the daily practice of architecture, which includes design competitions to which architects, building engineers and urbanists frequently submit their works and which are reviewed by a jury of peers. In many countries these competitions are strictly regulated. The jury assessments are not based on intuition, ideas or ideology but on explicit criteria; the very same criteria that the committee claims do not exist. Moreover, the review committee fails to debunk a myth which suggests that staff spend their time and

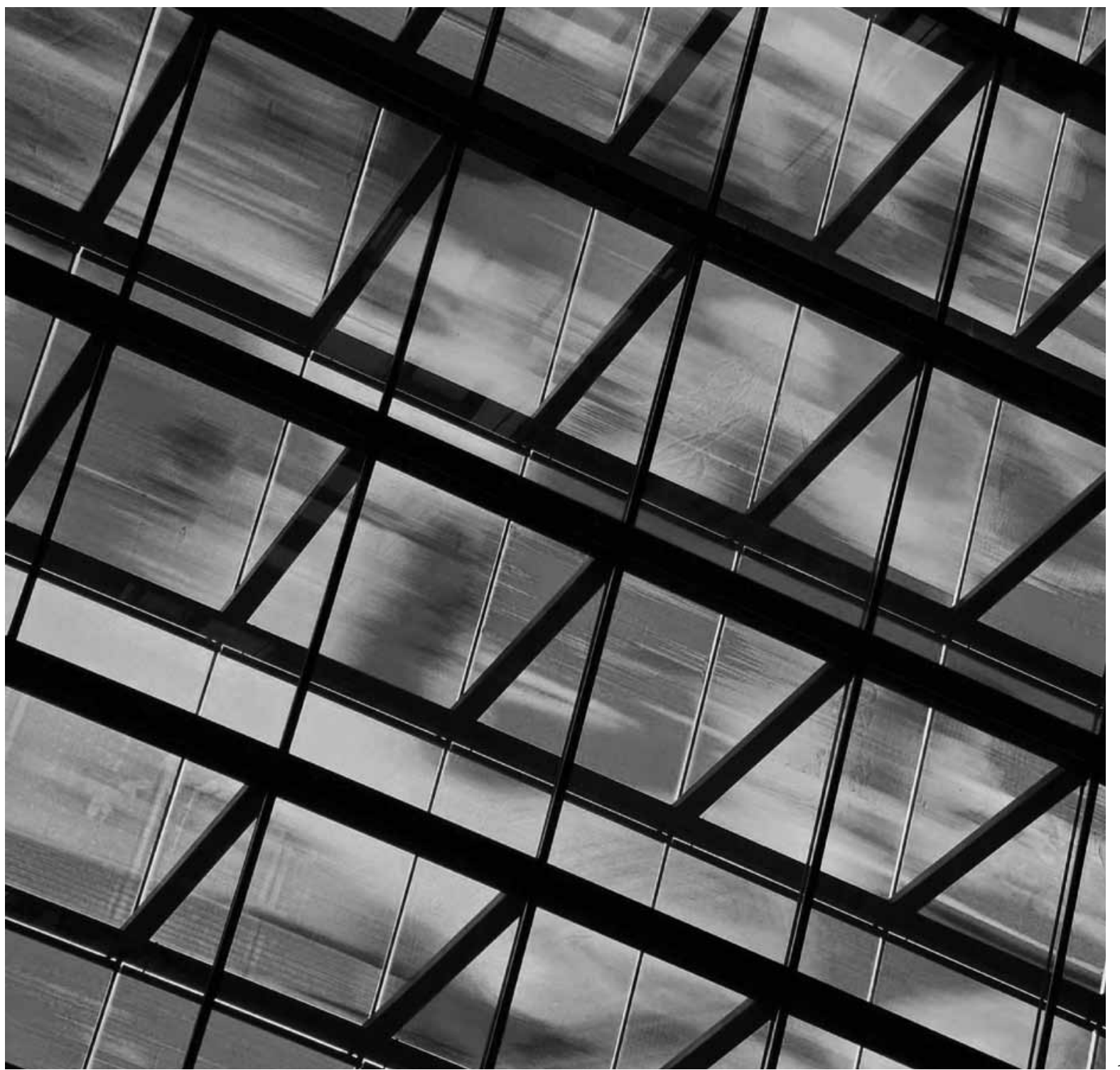


energy on producing designs instead of producing other scientific output. In fact, the number of designs produced by the Faculty of Architecture is limited, if we exclude designs that result from education or professional work. The most troubling aspect of the 1997 assessment is that it resulted in a major setback for those who are of the opinion that architecture indeed represents a mature field of science. The review committee seems to contradict that opinion. Similarly, the 1997 assessment provides a justification for those who prefer not to comply with generally accepted academic principles. The argument that proper assessment of architecture cannot be based on academic principles is an argument you might expect from those who would not expect to fare well in such an assessment, but certainly not from a review committee itself. As such, research in architecture became the victim of the first attempt to measure its level of performance.

\section{A future for the humanities without architecture}

In 2008, the National Plan for the Future of the Humanities (National Plan) was published by order of the Dutch Ministry of Education, Culture and Science. ${ }^{4}$ The plan was written by a committee chaired by Job Cohen, who at that time was mayor of Amsterdam and is now the leader of the Social Democrats in the Dutch parliament. The National Plan described both the value and the position of the study of the humanities in the Netherlands, provided a frame of reference for decisions regarding the sustainability and quality of practice of the humanities with the aim of safeguarding the continuity of those disciplines, and helped develop a new and vibrant future for the humanities.

Remarkably, the National Plan is headed by a fullbleed image of the CCTV building that was designed by Rem Koolhaas' Office for Metropolitan Architecture (OMA) and ends with yet another full bleed image of the design for The Netherlands Institute for Sound and Vision that was designed by Michiel Riedijk, Professor of Architecture at Delft [1]. ${ }^{5}$

The word 'architecture', however, is notably absent in the text of the National Plan. Consequently, the Faculty of Architecture, which is part of a 'university of technology', is ineligible for the funding provided under the National Plan: $€_{10}$ million in 2010 and $€_{15}$ million per year from 2011 in structural funding. Of that funding, $€_{5.625}$ million will be set aside until 2014 to co-fund a Ph.D. programme with an expected total cost of $€_{16.875}$ million. The Ph.D. programme is managed by the NWO, ${ }^{6}$ which will contribute two thirds of the total funds for the programme (or $€_{11.25}$ million) from its own resources. The Delft and Eindhoven Faculties of Architecture cannot access any of this public funding. However, the review committee's diagnosis does describe some of the issues inherent to the practice of architecture research today. For instance, the National Plan discusses the inadequacy of tools available for quality assessment in relation to the output that is expected in humanities research.

The humanities have a publication culture of their own, in which the monograph occupies a prominent place. Within the humanities, articles in English focused solely on peers in refereed academic journals do not have the predominant role they do in some other academic fields. In that it produces sixty books per year (compared with fifteen ISI journal articles) and maintains a strong focus on Dutch journals (many of which blur the lines between academic and professional writing), the Faculty of Architecture may seem more like a faculty in a humanities university than a faculty in a university of technology. However, this does not change the fact that the Faculty of Architecture is part of a university of technology and, thus, must face all the associated challenges.

\section{Performing arts}

The challenges that architecture research faces are similar to those faced by other fields, such as those we commonly refer to as the 'creative arts'.

The question of what is research in the creative arts is one that has special significance in Australian universities today but little significance elsewhere. Its importance lies in the fact that there are scarce dollars attached to the definitions of research. This has led to the need to define research in the creative arts in ways that will give the creative arts in universities a foothold in the competition for research dollars. Attempts to force mainstream creative arts activities into the mould of scientific research has led to semantic arguments that often have not been particularly helpful. However, with only two funded categories - teaching and research - the opportunities for alternative arguments have been limited. ${ }^{8}$

In his influential report on 'Research in the Creative Arts', Dennis Strand tackles the issues that the Australian performing arts were facing a decade ago; a complex and highly political terrain. The definition of research in the field of architecture is rather straightforward when compared with definitions of research in the fields such as music or dance. Strand proposes a pragmatic solution to move forward the discussion in Australia. He introduces the notion of research equivalence, bypassing the discussion of whether artistic performance activities fit in with the way that universities and funding bodies commonly understand research. Instead of reworking that definition he extends it by adopting terms such as 'research activity' and 'research equivalent activity'. He defines 'research activity' as work of a traditional scholarly or scientific nature, which normally aspires to verifiable statements, and to being unambiguous in interpretation, while 'research equivalent activity' should be understood as the work of a fundamentally creative type, which often aspires to open-ended or interpretive statements, open to multiple interpretations. Strand refers to the work of Vella and de Haan on the differentiation between professional practice and research activity in music, where performance is related to repertoire, technological developments, culture and historical critiques. ${ }^{9}$ From here on, he develops an intriguing checklist that distinguishes between performancebased research/research equivalent activities and performance-based professional practice, as shown in Table $1 .^{10}$ 
TA Creative Arts Research/Research Equivalent

Checklist for Performance

To what extent does the performance meet the following criteria?

Advancement or extension of knowledge

To what extent:

is the performance creating new or extending old repertoire?

does the performance represent an ongoing critical investigation?

New discoveries

To what extent:

does the performance involve the presentation of a new work?

does it involve new approaches to the discipline's design?

Innovative ideas, techniques, technologies

To what extent:

do the performers explore new 'writer'-performer relationships?

does the performance challenge pre-existing attitudes in the areas?

does the performance explore new discipline techniques?

Solutions to problems

To what extent does the performance provide innovative solutions to problems of the discipline?

Refinements or reinterpretations of methods, techniques, existing knowledge

To what extent does the performance explore new relationships of the human body to the instrument or technological interface?

Conceptual advances

To what extent does the work provide a significant contribution to performance techniques, attitudes or interpretations?

Constructive critiques and synthesis

To what extent:

does the performance provide an example of a major series representing a particular perspective?

does the performance involve a significant amount of responsibility in direction, conducting or arrangement?

does the performance demonstrate a thorough researching of source materials in its documentation?

does the performance provide a new source for creating links between seemingly disparate repertoires?

(e.g. popular music with early music)?

New means of dissemination

To what extent:

are the performers explicitly exploring new means of presentation?

does the performance explore new audience contexts?

Table 1. A creative arts research checklist

\section{Evaluating research in context}

Clearly, architecture is not the only academic field that struggles with the perceived divide between performance and measured performance. This type of 'evaluation gap' poses a delicate problem for organisations that are responsible for managing public research funding, such as the Australian Research Council (ARC) and the Netherlands Organisation for Scientific Research (NWO). Excluding a specific discipline or even an entire faculty from funding may create a political problem that can require immediate attention. It is this context in which the idea emerged that the 'evaluation gap' can be bridged if assessments review the social impact of research on equal terms as the scientific quality of research.

One initiative used to measure the societal impact of research in this context emerged from the work of the Consultative Committee of Sector Councils for Research and Development. The project was called 'Evaluating Research in Context' (ERiC) and represented a joint initiative between the Royal Netherlands Academy of Arts and Sciences (KNAW), the Netherlands Organisation for Scientific Research (NWO), the Association of Universities in the
Netherlands (VSNU) and the Netherlands Association of Universities of Applied Sciences (HBO-raad). The stated objectives of the ERiC project were manifold and included the following:

ERiC develops and disseminates information about how to measure the social impact of research.

ERiC raises awareness of the possibilities for assessing the social impact of research.

ERiC develops methods for measuring the social impact of research, by carrying out projects with universities and universities for applied sciences. ${ }^{11}$

ERiC's objective, which represented a relatively new phenomenon, was to explore how to measure the social impact of research. Funding organisations have become sensitive to societal demands in the wake of 'grand challenges' such as economic recovery and climate change. This sentiment is reflected in the 2010 PPP-calls by the EU's Seventh Framework Programme, which addressed topics such as Energy-efficient Buildings, Factories of the Future, the European Green Cars initiative and the Future Internet project. ${ }^{12}$ The description of research that emerged from the ERiC project was broader than the description that had been originally requested under the prevailing standard 
evaluation protocol (SEP). The participation of the KNAW, the NWO and the VNSU ensured that the ERiC's findings would become part of an amended protocol.

The follow-up to ERiC is SIAMPI, a project by an international consortium, consisting of KNAW, the Rathenau Institute, INGENIO (CSIC-UPV), Les Maisons de Sciences de l'Homme and the Manchester Institute of Innovation Research. Funded in 2009 by the European Commission's seventh research framework programme, SIAMPI is expected to provide insight into productive interactions between researchers and society, to further develop approaches and tools for the assessment of social impact, and to disseminate scientific results and insights from the project among the bodies involved in the evaluation of research. ${ }^{13}$

\section{Architecture pilot}

The ERiC project developed its ideas through pilots. In late 2007, Jacob Fokkema, Rector Magnificus of the Delft University of Technology (TU Delft), initiated an ERiC pilot at the Faculty of Architecture.

The Faculty of Architecture perceives a serious conflict between the demands and criteria in evaluation procedures and the ambition to be relevant for the practice of architecture, planning and building. The goal of this ERiC pilot is to develop an evaluation method that judges research in the Faculty of Architecture on all its merits and takes into account the specific characteristics of architecture research. ${ }^{14}$

The pilot was conducted by researchers from the Rathenau Institute, an autonomous organisation funded by the Ministry of Education, Culture and Science. The responsibility for its governance is vested in the KNAW. The fields studied at the Rathenau Institute include technology assessment and science system assessment. The Rathenau Institute goals are to assist in the political decisionmaking regarding the social, ethical and political impacts caused by modern science and technology and to study the way the science system responds to scientific, social and economic developments.

The Rathenau Institute's work at the Faculty of Architecture consisted of three phases. In the first phase of the pilot, the concept of 'designoriented research' was investigated. In the second phase, the formulation of assessment criteria was investigated. In the third phase, the assessment criteria from phase two were tested by evaluating two research groups.

The main focus of the Faculty of Architecture's 'design-oriented research' is not understanding for the sake of understanding, but rather to understand in order to be able to change or optimise what is understood by means of design, engineering, planning or management in architecture and the built environment. The Rathenau Institute identified four types of research favoured at the Faculty of Architecture; the four types of research were evaluation research, historical research, conceptual research and practical research:

1. Evaluation research, which is characterised as the empirical study of existing objects and processes. It analyses the effects and consequences which manifest themselves once architectural objects or processes have been realised.

2. Historical research, which interprets, understands and explains designs, while taking site characteristics into account.

3. Conceptual research is exploratory and experimental and aims at innovative, revolutionary concepts, manifestos and visions of the built environment.

4. Practical research is research done for educational purposes and for professional practices and refers to the research architect's need to find optimum solutions for certain building assignments. ${ }^{15}$

Each research type has its own specific methodologies, outputs and relationships with both scientific literature and architectural practices, shown in Table $2 .{ }^{16}$

In the second phase of the pilot, the Rathenau Institute and the Faculty of Architecture developed improved indicators for use in reviewing the

\begin{tabular}{|c|c|c|c|c|}
\hline & Historical research & Evaluation research & Conceptual research & Practical research \\
\hline \multirow[t]{3}{*}{ Texts } & Books & ISI Publications & Conference Proceedings & \\
\hline & & Professional Publications & & \\
\hline & & Policy Reports & & \\
\hline \multirow[t]{2}{*}{ Non-texts } & Exhibitions (and catalogues) & Tools & Exhibitions (and catalogues) & Exhibitions (and catalogues \\
\hline & & & $\begin{array}{l}\text { Designs (Drawings/ } \\
\text { Computer Animations/ } \\
\text { Scale Models/Prototypes) } \\
\text { buildings or constructions }\end{array}$ & $\begin{array}{l}\text { Designs (Drawings/ } \\
\text { Computer Animations/ } \\
\text { Scale Models/Prototypes) } \\
\text { buildings or constructions }\end{array}$ \\
\hline $\begin{array}{l}\text { Scientific } \\
\text { stakeholders }\end{array}$ & Peers & Peers & Peers & \\
\hline \multirow{5}{*}{$\begin{array}{l}\text { Social } \\
\text { stakeholders }\end{array}$} & & Architects & Architects & \multirow{5}{*}{$\begin{array}{l}\text { Client who } \\
\text { commissioned the work }\end{array}$} \\
\hline & & Urban Designers & Spatial Planners & \\
\hline & & Spatial Planners & Building Contractors & \\
\hline & & Building Contractors & Building Managers & \\
\hline & & $\begin{array}{l}\text { Governments (Municipalities/ } \\
\text { Provinces/National } \\
\text { Government) }\end{array}$ & $\begin{array}{l}\text { Governments (Municipalities/ } \\
\text { Provinces/National } \\
\text { Government) }\end{array}$ & \\
\hline
\end{tabular}


scientific quality and societal relevance of architecture research. These indicators were to be tested in the third phase of the project and included scientific quality, scientific production, scientific recognition, responsiveness of agenda setting, collaboration with (potential) users, dissemination and knowledge transfer related to the mission and actual results, and the impact and use of research.

The third phase proved more difficult than anticipated. After new performance indicators were identified, an unexpected challenge emerged; the data associated with these indicators was not available. Over the years, the Faculty had meticulously archived all of the output data necessary to address the prevailing standard evaluation protocol, including information on ISI publications, books and conference proceedings. Systematic data on key exhibitions, keynotes, consultancy roles, prestigious prizes and important dissemination events were not recorded and the research groups were unable to determine that data in the limited time allotted to them; and this problem was aggravated by a parallel restructuring of the research portfolio. The Rathenau Institute was justified in its concluding criticism of both aspects of the process. However, the conclusions of the Rathenau Institute failed to take into account the fact that, in the course of the ERiC pilot, on 13 May 2008, the thirteen-storey building occupied by the Delft Faculty of Architecture burnt to the ground. The building's destruction made the task of finding evidence of past performance significantly more

\begin{tabular}{|c|c|c|c|}
\hline & SEP item & SEP explanation & Results of ERiC pilot \\
\hline 1 & \multirow{2}{*}{$\begin{array}{l}\text { Objectives and } \\
\text { research area }\end{array}$} & Vision, mission and objective(s) of the institute & \multirow{2}{*}{$\begin{array}{l}\text { Relevance of research agenda with regard to societal } \\
\text { issues and for stakeholders }\end{array}$} \\
\hline & & Research area and programmes & \\
\hline \multirow[t]{4}{*}{2} & \multirow[t]{4}{*}{ Composition } & $\begin{array}{l}\text { Composition of the research unit to be evaluated based } \\
\text { on two indicators }\end{array}$ & $\begin{array}{l}\text { Staff with part-time positions at external organisations } \\
\text { (architecture bureaus, policy bodies, consulting firms) }\end{array}$ \\
\hline & & \multirow{2}{*}{$\begin{array}{l}\text { - total number of employees in each job category } \\
\text { (including contract-Ph.D. candidates) and }\end{array}$} & Specify: \\
\hline & & & - Commissioned research by societal actors \\
\hline & & $\begin{array}{l}\text { - overview of the various sources of financing } \\
\text { (internal and external) }\end{array}$ & $\begin{array}{l}\text { - Earmarked/structural funding related to societal } \\
\text { concerns/issues }\end{array}$ \\
\hline \multirow[t]{3}{*}{3} & \multirow{3}{*}{$\begin{array}{l}\text { Research environment } \\
\text { and embedding }\end{array}$} & \multirow{3}{*}{$\begin{array}{l}\text { National and international positioning } \\
\text { ('soft' benchmarking based on SWOT analysis), } \\
\text { - number and affiliation of guest researchers } \\
\text { (internally and externally funded) }\end{array}$} & - Actual collaboration with stakeholders \\
\hline & & & - Participation in consortia \\
\hline & & & \\
\hline \multirow[t]{4}{*}{4} & \multirow[t]{4}{*}{$\begin{array}{l}\text { Quality and scientific } \\
\text { relevance }\end{array}$} & $\begin{array}{l}\text { - 3-5 most significant results/highlights relevant to } \\
\text { the discipline per group/subgroup }\end{array}$ & $\begin{array}{l}\text { - 3-5 outputs with major impact on architectural } \\
\text { practices and policies }\end{array}$ \\
\hline & & $\begin{array}{l}\text {-3-5 key publications per group/subgroup (references; } \\
\text { full text may be published on secluded website) }\end{array}$ & \\
\hline & & $\begin{array}{l}\text { - Number of articles in top } 10 \% \text { of publications relevant } \\
\text { to the discipline; same for top } 25 \%\end{array}$ & \\
\hline & & $\begin{array}{l}\text { - 3-5 most important books or chapters of books } \\
\text { insofar as applicable }\end{array}$ & \\
\hline \multirow[t]{3}{*}{5} & \multirow[t]{3}{*}{ Output } & - Number of publications & - Number of conference papers \\
\hline & & - Number of Ph.D.s (completed and in progress) & - Edited volumes of conference papers \\
\hline & & $\begin{array}{l}\text { - Use (number of users) of research facilities } \\
\text { (if part of institute's mission) }\end{array}$ & - Number of major reviews of literature and exhibitions \\
\hline 6 & Earning capacity & $\begin{array}{l}\text { Acquiring projects and programmes through competitive } \\
\text { funds: public and private, national and international }\end{array}$ & - \\
\hline \multirow[t]{2}{*}{7} & \multirow[t]{2}{*}{ Academic reputation } & \multirow{2}{*}{$\begin{array}{l}\text { Most important signs of recognition for research staff } \\
\text { (prizes, awards, invitations to speak at major conferences, } \\
\text { conference organisation activities, editorships, } \\
\text { membership in academies) }\end{array}$} & $\begin{array}{l}\text { Professional reputation, based on roles in professional } \\
\text { contexts, policy-making etc. }\end{array}$ \\
\hline & & & $\begin{array}{l}\text { Include stakeholder feedback on quality of the } \\
\text { group if available }\end{array}$ \\
\hline \multirow[t]{5}{*}{8} & \multirow{5}{*}{$\begin{array}{l}\text { Societal relevance: } \\
\text { quality, valorisation } \\
\text { and impact }\end{array}$} & \multirow{5}{*}{$\begin{array}{l}\text { Socio-cultural and/or technical or economic } \\
\text { quality, impact, valorisation }\end{array}$} & This section includes four issues: \\
\hline & & & $\begin{array}{l}\text { - The most significant knowledge contributions made in } \\
\text { the review period to architectural practices and policies }\end{array}$ \\
\hline & & & $\begin{array}{l}\text { - Evidence of the appreciation of stakeholders of these } \\
\text { contributions }\end{array}$ \\
\hline & & & $\begin{array}{l}\text { - Strategies for disseminating these contributions } \\
\text { (outputs, media) }\end{array}$ \\
\hline & & & - Evidence of impact of these contributions \\
\hline 9 & Viability & $\begin{array}{l}\text { Viability of the unit to be evaluated in terms of resource } \\
\text { management, available infrastructure and innovative capacity }\end{array}$ & - \\
\hline 10 & Next generation & Information about Ph.D. training & - \\
\hline 11 & SWOT-analysis & Procedure associated with the SWOT analysis and outcomes & - \\
\hline 12 & Strategy & Based on the SWOT analysis & - \\
\hline
\end{tabular}

Table 3. Additional guide for SEP self-evaluation by architecture research groups 
difficult as most of it was destroyed. The Faculty's staff were scattered throughout the campus for a period of almost six months, and the negative effect this had on the faculty's organisation was apparent. Nonetheless, the comments did make sense and were addressed in time for the 2010 research assessment.

In addition to conducting its three-step programme, the Rathenau Institute conducted a benchmark study of the incidence of publications by TU Delft Architecture and international faculties in architecture-related scientific journals. The benchmark study produced few new insights; it merely confirmed what most researchers in Delft already knew:

[...] there is no stable publication pattern nor a core set of scientific journals to make a valid bibliometric benchmarking of architectural departments. Only a small sample of scientific journals is covered by ISI databases. Although these data can be included in an evaluation report, clearly for an assessment of the research quality of the programs, information about program, other scientific outputs and good peer assessment will be required and are of more value. ${ }^{17}$

\section{Research assessment 'Architecture \& the Built Environment'}

The ERiC pilot helped the Faculty of Architecture to bring the presentation of societal relevance on a par with the presentation of scientific quality. The pilot developed an overview of relevant indicators. Jointly with the Rathenau Institute, the Faculty integrated these criteria into the format for self-evaluation ${ }^{18}$ that is included in the new Standard Evaluation Protocol (SEP 2009-2015) ${ }^{19}$ The additional guide for SEP self-evaluation by architecture research groups is shown in Table $3 .^{20}$

The SEP 2009-2015 takes an evolutionary step, clearing the way for a concise 'mean and lean' selfevaluation. The research assessment entitled 'Architecture and the Built Environment 2010' is one of the first assessments under the new SEP, and it is the first that implemented the insights offered by the ERiC-project.

The prospect of yet another research assessment did not elicit much enthusiasm at TU Delft. Due to past negative experiences, the staff did not immediately recognise the strategic opportunity presented by incorporating additional performance indicators (as identified by the ERiC project) into their mandatory self-evaluation. The Faculty faced the challenge of motivating its staff to produce the missing data related to the ERiC pilot's performance indicators and to deliver a selfevaluation that truly reflected the creativity and innovation of its design-oriented research. To get this process moving, the faculty decided to produce a high-quality book in the tradition of architecture research, using graphic design to organise the copious amounts of available information and communicating the identities of the various research groups involved. With 1000 copies printed, the book provides a point of reference for research performance and excellence in architecture and the built environment and can be read as a structured effort to establish a benchmark in its field [2]. ${ }^{21}$

The actual site-visit occurred between 22 November and 25 November 2010 at TU Eindhoven, TU Delft and the Berlage Institute. ${ }^{22}$ In accordance with the faculty's new policy of promoting openness, all the sessions conducted between the review committee and the Delft research groups were public; a strategy that worked remarkably well. During the site visit at TU Delft on 23 November, staff members joined each other's sessions. Twenty to thirty visitors witnessed each session. On 25 November, the chairman of the review committee (Peter Russell, the Dean of the RWTH Aachen Architecture Faculty) provided his initial feedback, which detailed the review committee's findings. The session was streamed live to Eindhoven using the TU Delft Collegerama system and has remained available online since the date of its publication. ${ }^{23}$ Altogether the Faculty for Architecture and the Built Environment made a very good impression on the committee.

\section{The 2010 KNAW TWINS-advice}

During the period that the ERiC project was ongoing, the 3TU Federation (3TU) asked the Royal Netherlands Academy of Arts and Sciences (KNAW) to provide input on the proper criteria used in ex-ante and ex-post assessments of research output in both design and engineering. The 3TU is the umbrella organisation for the three leading universities of technology in the Netherlands: Delft University of Technology, Eindhoven University of Technology and the University of Twente. The reason for asking the KNAW for input may sound familiar:

Scientists in design and engineering regularly encounter problems in the assessment of the quality of their research output, whether that assessment takes place within the context of an external evaluation, an academic appointment or promotion, or an application for funding. The quality indicators used in such situations are borrowed from the more basic sciences (publication in ISI journals, impact factors, citations, the Hirsh Index) and are, in the eyes of these scientists, inadequate. ${ }^{24}$

In late 2010, immediately following the 2010 research assessment for architecture and the built environment, KNAW's Council for the Technical Sciences, Mathematics, Physics, Astronomy and Chemistry (TWINS) published its advisory report. Initially, the KNAW TWINS Council considered the following five criteria, which were established by the Royal Academy of Engineering: (i) publications, (ii) impact, (iii) innovativeness, (iv) the involvement of external stakeholders, and (v) the reputation of the scientists involved. However, the KNAW TWINS Council concluded that in design and engineering disciplines, the criteria used could be narrowed down to just two criteria: (i) scientific quality and (ii) societal relevance, which are the same criteria that are currently used by the SEP. According to the council, assessing quality should be a question of fine-tuning, owing to the differences between the disciplines (including their publication cultures), 
categories of scientific activity (design, research) and assessment situations (external evaluation, appointment, research proposal). The advisory report presented an overview of these indicators, shown in Table $4 .^{25}$

Although the advisory report provides a detailed overview of the indicators to be used for assessing scientific quality and societal relevance, the KNAW TWINS Council advises the board of the 3TU:

to create sufficient scope for discipline-specific quality assessment in the technical sciences, and to ask the design and engineering disciplines to identify the indicators and their relative importance for assessing quality in those disciplines. These indicators must be credible in an international context. ${ }^{26}$

As part of both the ERiC pilot and the subsequent research assessment, the Faculty of Architecture did indeed identify such indicators. The KNAW TWINS Council advises the funding bodies:

to devote more attention to programmes for disciplines that do not fit easily into existing disciplinary categories and the present quality assessment method. This applies in particular to the design and engineering sciences. The quality indicators used must do justice to these disciplines. ${ }^{27}$

Finally, the KNAW TWINS Council advises scientists in the design and engineering disciplines:

to do their utmost to promote a culture of peer-reviewed publications wherever necessary. Such publications can serve to verify results, disseminate knowledge and contribute to the 'scientification' of the discipline. ${ }^{28}$

Covering peer-reviewed architecture periodicals Publications in peer-reviewed academic journals are increasingly used as an indicator of both the quality and the productivity of a research group. The Delft Faculty of Architecture is part of a university that includes, among other disciplines, chemistry, geosciences, applied physics, mathematics and engineering. TU Delft's internal allocation of

\begin{tabular}{|c|c|c|}
\hline & Indicators for output & Indicators for person \\
\hline \multirow[t]{15}{*}{ Scientific quality } & Scientific publications & Recognition by scientific community \\
\hline & $\begin{array}{l}\text { Articles in peer-reviewed journals (no. and type } \\
\text { of journals) }\end{array}$ & $\begin{array}{l}\text { Membership in prominent organisations such as } \\
\text { academies }\end{array}$ \\
\hline & \multirow{2}{*}{$\begin{array}{l}\text { Articles in peer-reviewed conference proceedings } \\
\text { (no. and type of proceedings) }\end{array}$} & of sciences \\
\hline & & Prestigious grants (VENI, VIDI, VICI, or ERiC Grants) \\
\hline & $\begin{array}{l}\text { Scientific books published by leading publishers or } \\
\text { significant contributions to such books (no. and type) }\end{array}$ & Editorships \\
\hline & Citations of individual articles & \multirow{2}{*}{$\begin{array}{l}\text { Chief/full editorship of international scientific journal/book/ } \\
\text { conference proceedings }\end{array}$} \\
\hline & Impact factors of journals in which articles are published & \\
\hline & Other outnut & Considered expert by peers \\
\hline & \multirow{2}{*}{$\begin{array}{l}\text { Peer-reviewed artefact (design) + documentation. } \\
\text { This also includes software design }\end{array}$} & $\begin{array}{l}\text { Advisory role capacity in scientific circles (NWO, external } \\
\text { inspections, etc.) }\end{array}$ \\
\hline & & Keynote lectures at science conferences \\
\hline & Research impact (ex-post) & Membership on programme committees \\
\hline & $\begin{array}{l}\text { Use of scientific products by other researchers } \\
\text { (artefacts, methods, measuring instruments, tools, } \\
\text { standards and protocols) }\end{array}$ & $\begin{array}{l}\text { Participation in international assessment committees for } \\
\text { scientific programmes/institutes or scientific advisory } \\
\text { councils/institutes }\end{array}$ \\
\hline & Potential research impact & Research imnact durinathe course of career \\
\hline & $\begin{array}{l}\text { Possible contribution to development of theories and } \\
\text { models, methods, operational principles or desian concepts }\end{array}$ & Person's citation score \\
\hline & & Contribution to developing a 'school of thought' \\
\hline \multirow[t]{18}{*}{ Societal relevance } & \multirow{2}{*}{$\begin{array}{l}\text { Use of results by external stakeholders } \\
\text { (ex-post impact) }\end{array}$} & Considered expert by external stakeholders \\
\hline & & Advisory and consultancy work (focused on users) \\
\hline & \multirow{2}{*}{$\begin{array}{l}\text { Contribution to solving societal problems } \\
\text { Market introduction and new projects in industry }\end{array}$} & \multirow{2}{*}{$\begin{array}{l}\text { Leading position in industrial research (e.g., managing } \\
\text { director of R\&D department) }\end{array}$} \\
\hline & & \\
\hline & \multirow{4}{*}{$\begin{array}{l}\text { Spin-offs in industry } \\
\text { Patents used } \\
\text { Artefacts used (designs, software) }\end{array}$} & \multirow{4}{*}{$\begin{array}{l}\text { Considered expert by profession } \\
\text { Oeuvre prizes (e.g., for architects) } \\
\text { Retrospective exhibitions }\end{array}$} \\
\hline & & \\
\hline & & \\
\hline & & \\
\hline & Use if results by profession (ex-post impact) & Contribution to knowledge dissemination \\
\hline & \multirow[t]{2}{*}{$\begin{array}{l}\text { Use of artefacts, methods, measuring instruments, tools, } \\
\text { standards and protocols }\end{array}$} & $\begin{array}{l}\text { Activities focusing on popularisation of science, education } \\
\text { and contribution to public debate }\end{array}$ \\
\hline & & Training of professionals \\
\hline & $\begin{array}{l}\text { Involvement of external stakeholders in scientific } \\
\text { output (potential societal relevance) }\end{array}$ & Ph.D.s with their first job in relevant practice \\
\hline & $\begin{array}{l}\text { Businesses or civil-society organisations involved in } \\
\text { guiding research projects (e.g., on user committees) }\end{array}$ & \\
\hline & Contract financing by potential users (e.g., industry) & \\
\hline & Public financing related to societal questions & \\
\hline & Valorisation grants & \\
\hline & Contribution to knowledge dissemination & \\
\hline & $\begin{array}{l}\text { Professional publications and papers, non-scientific } \\
\text { publications, exhibitions and other events related to } \\
\text { research results }\end{array}$ & \\
\hline
\end{tabular}


research funding provided an incentive for highquality research output from 1994 to 2009. This system of allocation (supervised by the TU Delft BTA committee) emphasises articles published in journals that are included in Thomson Reuters ISI Citation Indexes (such as the SCI, SSCI or AHCI). Articles in journals with a high impact factor received significant bonuses compared with articles in other publications. This practice, which was recently abolished, had a significant impact on how the quality of architectural research was perceived in Delft.

Performance in high-ranking ISI journals became an important indicator for comparing the different faculties. While the Faculty of Architecture produced about fifteen ISI publications per year, the number for the Faculty of Applied Sciences was around 600 ISI publications per year. Comparing the coverage of both the arts \& humanities and 'other social sciences' with the coverage of chemistry, geosciences, applied physics and mathematics indicates that architecture hardly stands a chance against the other Delft faculties. Architecture has the poorest coverage in the ISI indexes of all disciplines represented in the university, as shown in Table $5 .{ }^{29}$

If one considers which architectural journals are actually included in the ISI citation indexes, then the situation appears to be even more sobering. Among the periodicals that are included in the ISI are the notorious Architectural Digest, the colourful Architecture + Urbanism and the glossy L'Architecture d'Aujourd'hui. These periodicals are well-known and well-distributed to both the general public and professionals. However, these titles certainly do not represent peer-reviewed academic journals. The fact that they are included in the ISI suggests there are no rigorous transparent quality criteria in place that govern the ISI's Arts \& Humanities Citation Index (AHCI). Academics in the field of architecture face a dilemma similar to that which was caused by the 1997 review committee: those who choose not to comply with the generally accepted standards (such as the need to publish in peer-reviewed journals) may cite the shortcomings of the ISI, discredit such indexes and continue with their own publication habits, whereas those who choose to comply must publish their research either in academic publications that are not indexed (and thus not measured) or in ISI journals that are not part of their own domain (thus alienating themselves from their peers).

The requirement that academics publish in peer- reviewed academic journals is clearly upheld by both the 2010 review committee and the KNAW TWINS Council. Doubting whether the Thomson Reuters ISIindexes could deliver the required framework, TU Delft's Faculty of Architecture turned to Elsevier's SCOPUS instead. SCOPUS, the ISI's emerging competitor, is focusing on areas where the ISI's coverage is weak. SCOPUS offers an open and transparent procedure for submitting journal titles to be considered for inclusion in the index. Moreover, SCOPUS has agreed to work with TU Delft to systematically identify journals in the field of architecture and the built environment. This process is as challenging as the process of introducing new assessment indicators. After identifying an entry point in a major index, awareness needs to be created among publishers, to encourage them to cooperate with the journal selection process and to amend their editorial practices if necessary. This will not happen spontaneously and may prove a larger task than expected. It will however be beneficial to schools of architecture in Europe and beyond and worth the effort.

\section{Funding formulas}

There seems no other option than to embrace the key practices already adapted by mainstream sciences if schools of architecture want to do better at obtaining national research funding. Doing better means producing high quality proposals, supported by tangible evidence of research excellence: convincing performance in research assessments exercises and competitive publication records in international peer-reviewed scientific journals. Architecture should not focus blindly on ISI, impact factors or $\mathrm{H}$-scores.

The current task is firstly to ensure that the existing peer-reviewed journals in the field make it into the major indexes, allowing schools to improve the balance between professional and scholarly publications, without abandoning the serials they are already publishing in. Performing well in research assessment exercises depends in part on being allowed to present the full scope of research evidence, including book publications, expositions, design and engineering work. The broad set of performance indicators used in the 2010 Netherlands research assessment exercise on Architecture and the Built Environment worked well in that respect. Emphasising the strengths of architecture's societal relevance results in a more balanced picture of research performance. The support of the Netherlands Organisation for Scientific Research (NWO) and the Royal Netherlands

\begin{tabular}{llll}
\hline $\mathbf{8 0 - 1 0 0} \%$ & $\mathbf{6 0 - 8 0 \%}$ & $\mathbf{4 0 - 6 0 \%}$ & $\mathbf{4 0 \%}$ \\
\hline biochemistry \& molecular biology & applied physics \& chemistry & mathematics & other social sciences \\
\hline biological sciences - human biology & animals \& plants sciences & economics & arts \& humanities \\
\hline chemistry & psychology \& psychiatry & engineering & \\
\hline clinical medicine & geosciences & & \\
\hline physics \& astronomy & social science - medicine & \\
\hline
\end{tabular}




\begin{tabular}{|c|c|c|c|c|c|}
\hline Historical research & Evaluation rese & & Conceptual res & & Practical research \\
\hline Public funding & Public funding & Stakeholder funding & Public funding & Stakeholder funding & Client funding \\
\hline $\begin{array}{l}\text { Regular mainstream } \\
\text { programming humanities, } \\
\text { social sciences, } \\
\text { technical sciences }\end{array}$ & $\begin{array}{l}\text { Societal relevant } \\
\text { programming } \\
\text { based on } \\
\text { co-funding by } \\
\text { stakeholders }\end{array}$ & $\begin{array}{l}\text { Providing direct } \\
\text { funding or co-funding }\end{array}$ & $\begin{array}{l}\text { Dedicated } \\
\text { programming, } \\
\text { based on } \\
\text { co-funding by } \\
\text { stakeholders }\end{array}$ & $\begin{array}{l}\text { Direct funding or } \\
\text { co-funding by } \\
\text { stakeholders }\end{array}$ & Direct funding by clients \\
\hline
\end{tabular}

Table 6. Funding formulas for architecture research

Academy of Arts and Sciences (KNAW) has been instrumental in the recent policy advice that stresses the importance of the societal relevance of research (ERiC, TWINS). However, it remains to be seen whether those reports are going to influence the outcome of reviews on research proposals any time soon. The NWO often uses foreign reviewers who have little contextual knowledge of the point to which the current debate on the evaluation of research has advanced in the Netherlands. In response to one of the Faculty's more recent NWO research proposals one of these reviewers was so kind to note that:

[...] architectural design research might be considered rather peripheral to the core business of the university and sufficiently disconnected to be one of the few activities to be reduced/cut without damaging the rest of the institution.

Clearly, a different approach is required here. The Rathenau Institute identified four categories of architecture research: historical research, evaluation research, conceptual research and practical research. The debate on research quality and funding becomes more precise when we approach each of those categories independently of each other, reviewing funding formulas for each, as shown in Table 6. Evaluation research and historical research are the categories that stand to benefit the most from adapting standard scientific practices without having to give up much of their original identity. These research categories can be funded by mainstream programmes for the humanities, social sciences and technical sciences. In addition, evaluation research could benefit from a broad range of stakeholders with (co-) funding capacity. Mainstream programmes could make co-funding mandatory, thus increasing the number of initiatives it can support. Conceptual research, however, resembles the complexity of research found in the performing arts. Its output is not likely to be recognised in mainstream scientific programmes. The KNAW TWINS committee advised the funding bodies to initiate programmes for such disciplines that do not fit easily into existing categories. In dedicated programmes, architecture should be able to exploit the strong societal relevance of design and engineering. This may be possible with additional co-funding by major stakeholders. Practical research should be funded directly by clients, not by public research funds.

In all four categories, design should not try to present itself as equivalent to or a substitute for science. Instead, researchers and research groups should use design as an asset, as a unique selling point that allows them to distinguish their own scientific competence from that of others. With its societal relevance, with its ability to capture the imagination of the broader public, architecture should be well positioned to aim further than other fields as long it gets the basics of its own scientific foundations right. Indeed, architecture needs to do its homework first.

\section{Notes}

1. [n.a.], Standard Evaluation Protocol 2009-2015, protocol for research assessment in the Netherlands (Utrecht, VSNU, NWO, KNAW, 2009).

2. Architecture, Building and Planning, Series: Quality Assessment of Research (Utrecht, VSNU, 1998), p. 9.

3. Sebastian Macmillan, 'Architectural Research and its Enemies', arq (14.1), 2010, pp. 11-16

4. [n.a.], Sustainable Humanities, Report from the Committee on the National Plan for the Future of the Humanities (Amsterdam: Amsterdam University Press, 2009).

5. [n.a.], Sustainable Humanities.

6. [n.a.], Advies inzake Implementatie Duurzame Geesteswetenschappen, Aan Mevr. J. M. van BijsterveldtVliegenthart, Staatssecretaris van Onderwijs, Cultuur en Wetenschap 23 juni 2010 (Utrecht: Regieorgaan Geesteswetenschappen, 2010).

7. [n.a.], Sustainable Humanities.

8. Dennis Strand, 'Research in the

Creative Arts' (Canberra:

Department of Employment,

Education, Training and Youth

Affairs, 1998), pp. XV-XVI, accessed

online at <http://catalogue.nla.gov.

au/Record/364383> [accessed: 1

March 2011].

9. Richard Vella and Sidney de Haan,

Research, Music and Performance

(Hobart: University of Tasmania,

Conservatorium of Music, 1994).

10. Strand, Research in the Creative Arts, p. 52 .

11. NWO - Context Group - Evaluating

Research in Context, accessed online at <http://www.eric-project. nl/nwohome.nsf/pages/

NWOA_6TZJ28_Eng $>$ [accessed: 1 January 2011].
12. [n.a.], The European RTD Framework Programmes: From Economic Recovery to Sustainability, conference proceedings (Valencia: Spanish Ministry for Science and Innovation, 12-16 April 2010).

13. NWO - European consortium to measure impact of research on society, accessed online at < http:// www.nwo.nl/nwohome.nsf/pages/ NWOA_7RXCLC_Eng > [accessed: 1 March 2011].

14. Barend van der Meulen et al., Evaluating Research in Context: Pilot Study at the Faculty of Architecture TU Delft, Final Report: Confidential (The Hague: Rathenau Institute, 2010), p. 7 , accessed online at: <http:/| repository.tudelft.nl/view/ir/ uuid\%3Afoa 713f1-1564-4b79-be664f 5299ebba2c/> [accessed: 1 March 2011].

15. Frank van der Hoeven (ed.), 
Architecture and the Built Environment: Research in Context 2003-2009 (Delft: TU Delft Architecture, 2010), p. 15.

16. van der Meulen et al., Evaluating Research in Context.

17. Ibid.

18. [n.a.], Evaluating the Societal Relevance of Academic Research: A Guide, Series: ERiC publication, 1001 EN (KNAW, NWO, VSNU, Rathenau Institute, HBO-raad, 2010), pp. 20-21.

19. [n.a.], Standard evaluation protocol 2009-2015, protocol for research assessment in the Netherlands (Utrecht, VSNU, NWO, KNAW, 2009), accessed online at: <http:/| repository.tudelft.nl/view/ir/ uuid\%3A8fao7276-cf52-41f3aa7o-a 71678234424/> [accessed: 1 March 2011]

2o. [n.a.], Evaluating the Societal Relevance of Academic Research: A Guide.

21. van der Hoeven (ed.), Architecture and the Built Environment: Research in Context.

22. The Research Assessment Committee Architecture and the Built Environment in Delft, 25 November 2010 was chaired by Peter Russell, Dean at RWTH
Aachen. Members:John Worthington, Sheffield; Rachelle Alterman, Technion; Dirk Donath, Weimar; Per Heiselberg, Aalborg; Dinar Camotim, Lisbon; Pieter Uyttenhove, Gent; Michael Hebbert, Manchester; Nicholas Bullock, Cambridge. Secretary: Frank Zuijdam, Technopolis Group. [n.a.], Sustainable Humanities, p. 51, accessed online at: <www. regiegeesteswetenschappen.nl/ download/344.php >.

23. Collegerama < http://www.bk. tudelft.nl/sitevisit > [accessed: 1 January 2011].

24. [n.a.], Quality Assessment in the Design and Engineering Disciplines: A Systematic Framework, Series: Advisory report KNAW TWINS Council (Amsterdam, Royal Netherlands Academy of Art and Sciences, 2010), p. 9, accessed online at: <http://repository. tudelft.nl/view/ir/ uuid\%3Abcfa879d-0014-41d3-803893a1ec24e315/ > [accessed: 1 March 2011].

25. Ibid.

26. Ibid.

27. Ibid.
28. Ibid.

29. Henk F. Moed and Martijn S. Visser, Developing Bibliometric Indicators of Research Performance in Computer Science: An Exploratory Study Centre for Science and Technology Studies, Series: CWTS Report, 2007-01 (Leiden, CWTS 2007), p. 19.

\section{Illustration credit}

arq gratefully acknowledges: Amsterdam University Press, 1

\section{Biography}

Frank van der Hoeven is Director of Research at TU Delft's Faculty of Architecture. He was a member of TU Delft's BTA committee, facilitated the ERiC pilot in the Faculty of Architecture, coordinated Delft's 2010 Research Assessment, edited its selfevaluation, and was interviewed by the KNAW TWINS Council committee.

\section{Author's address}

Dr Frank van der Hoeven, Delft University of Technology Faculty of Architecture Julianalaan 134 2628 BL Delft The Netherlands f.d.vanderhoeven@tudelft.nl 